\title{
DOES COPYRIGHT HELP OR HARM CULTURAL DIVERSITY IN THE DIGITAL AGE?
}

Sean A. Pager

Michigan State University College of Law spager98@gmail.com

\begin{abstract}
Does copyright advance cultural diversity or inhibit it? Some blame copyright for fostering a global monoculture. Others contend that copyright enhances diversity by encouraging originality. Similarly opposing narratives exist regarding piracy: Some see piracy as an existential threat that will cripple cultural production; others argue piracy expands markets and exposes audiences to diverse content. This article reviews both theoretical and empirical literature on copyright's effects and on the conditions arising in copyright's absence. It argues that a regime of modest copyright protection, with appropriately tailored limitations, is likely to prove most conducive to copyright diversity. The Article concludes with a call to make the copyright system more hospitable to a particular source of cultural diversity: creative upstarts, a diverse class of creators who operate outside of the mainstream content industries.
\end{abstract}

\section{Keywords}

commons; creative industries; creativity; film; incentives; music; piracy

\section{About the Author}

Sean Pager is Professor of Law at Michigan State University, where he serves as Associate Director of the Intellectual Property, Communications and Information Law Program (IPIC). He earned his J.D. at U.C. Berkeley and an LL.M. at the European University Institute. 
Does copyright advance cultural diversity or impair it? Some blame copyright for fostering a global monoculture that represents the antithesis of diversity (MacMillan). Others contend that copyright enhances diversity by encouraging originality (Fishman). Similarly opposing narratives exist regarding piracy: Some see piracy as an existential threat that will cripple cultural production (Turow; Sherman); others argue that piracy can expand markets and expose audiences to diverse content (Sprigman and Raustiala 16-17; Parc, et. al. 141). Such diverging perspectives confounded the delegates who drafted the 2005 UNESCO Convention on Cultural Diversity. Unable to reach consensus, they ultimately deleted references to copyright from the final text, retaining only a cursory reference to intellectual property rights in the preamble (Hazucha, 108).

This article revisits the "copyright and diversity" debate in light of digital technologies' emergence in the decades since the UNESCO Convention was adopted. Assessing the effect of copyright has become, if anything, more confounding, given the shifting landscape of cultural production. Digitization has enabled new modes of creating and disseminating cultural works, novel forms of creativity, and innovative business models to fund them. Some commentators now see copyright as an obsolete model that imposes unacceptable costs on speech, innovation, and access to culture (Moglen; Boldrin and Levine). They argue that commons-based production will yield greater cultural diversity at a reduced social cost.

Drawing on both empirical and theoretical sources, this article examines the evidence in support of the copyright skeptics' position. It notes that answering whether copyright helps or harms cultural diversity turns in part on how one defines diversity. However, based on several plausible understandings of cultural diversity, the evidence supports a nuanced position. There are reasons to suspect that advanced economies such as the United States have been overprotecting copyright to the detriment of diversity. However, there are also reasons to think that eliminating copyright entirely and relying solely on commons-based production would impair cultural diversity in important respects. Accordingly, the optimal solution may be a modest copyright regime with appropriately tailored exceptions and limitations.

The argument that follows proceeds thus: Part One examines the relationship between copyright and cultural diversity, first theoretically and then empirically. Part Two considers alternative regimes based on open distribution and assesses their diversity implications. Part Three offers some normative conclusions and recommendations based on the findings of the prior parts. It focuses on the need to adapt the copyright system to better serve diverse creators and emphasize the need for procedural and institutional reforms that extend beyond the substantive law. 


\section{EXPLORING THE RELATIONSHIP BETWEEN COPYRIGHT \& DIVERSITY}

\section{A. The Elusive Concept of Cultural Diversity}

Cultural diversity is a widely recognized, albeit amorphous, policy objective. UNESCO's 2005 Convention on the Protection and Promotion of the Diversity of Cultural Expressions defines cultural diversity as referring to:

the manifold ways in which the cultures of groups and societies find expression ... manifest not only through the varied ways in which the cultural heritage of humanity is expressed, augmented and transmitted ... but also through diverse modes of artistic creation, production, dissemination, distribution and enjoyment.

Such broad, somewhat circular language offers little hint as to how to concretize diversity as a policy goal, let alone measure to progress toward achieving it (MacMillan). While scholars have proffered their own suggestions (Ranaivoson), in practice, different sorts of diversity tend to be emphasized in different contexts. In the United States, for example, diversity discourse typically focuses on media ownership, race, gender, and political viewpoint (Napoli 167). Other countries frame diversity primarily in terms of language and nationality (Napoli 172-73). The goals ascribed to cultural diversity policies are equally multifarious; they include burnishing national identities, fostering communal cohesion, ensuring minority representation, stimulating democratic discourse, promoting international understanding, and enriching global heritage (Pager, "Beyond Culture vs. Commerce" 71-72; Voon 47-59). While these goals are hardly mutually exclusive, they can conflict in particular instances. The normative ambiguities surrounding diversity thus serve to obscure the implicit tradeoffs and choices that policy-makers make (Street 381).

For example, is it more important to invest in high quality, avant-garde works that have a lasting impact versus works of popular entertainment that make an immediate contribution to the zeitgeist? Should cultural production strive to be inclusive in catering to minority subcultures, or should the priority be to unify the broader community? Do we care only about the diversity of the works produced, or does it matter who is making them? Is the goal only to ensure diversity of production, or should we care about consumption patterns? ${ }^{1}$

Such tensions and ambiguities complicate any assessment of copyright's impact, as will be seen below. There remains a further question of subject matter. Diversity policies have traditionally emphasized mass media works as opposed to fine arts (Burri 184). In order to focus the analysis further, this article confines its scope to 
the music and film industries. The question then becomes what is copyright's effect on music and film diversity?

\section{B. The Ambiguous Theoretical Effect of Copyright}

As noted above, the UNESCO delegates were unable to reach a consensus as to copyright's effect on diversity. There is a surprising lack of comprehensive analyses in the secondary literature as well. Cultural diversity debates typically focus on international trade law, media regulation, and cultural policy. Copyright scholars, for their part, are preoccupied with questions of efficiency, rather than diversity. Moreover, copyright law itself espouses a deep-rooted commitment to content neutrality that discourages inquiries into the comparative merits of creative works (Walker and DePoorter 344-45). When cultural diversity concerns arise in copyright discourse, they are often couched under alternative guises such as free speech or semiotic democracy. ${ }^{2}$ That said, the body of relevant materials is sufficiently large that only a partial summary can be provided here to illustrate some of the main lines of the theoretical debate.

Conventional wisdom has long held that intellectual property rights are necessary to incentivize innovation. Copyright serves to avert market failures due to free riding by copyists that would otherwise prevent creators from recouping their initial investments in creating and disseminating the work (Landes and Posner 326). Copyright exclusivity thus serves as an indirect subsidy to incentivize creative investments.

Does it therefore follow that more copyright means more creative works? And does more creative works mean more diversity? In fact, neither part of this syllogism necessarily holds true even in theory, let alone in practice.

Although the idea that more copyright means more creative production is widely held (Landes and Posner 339), what copyright really incentivizes is creative investments. Such investments may or may not translate into more new works. Some commentators stress copyright's value in ensuring that creators can work under conditions of creative autonomy (Merges 1263-65; Liu 520-29). Such autonomy may lead authors to invest greater time in perfecting their craft, resulting in fewer works, but higher quality output (Merges 1265-66). ${ }^{3}$

Critics, however, argue that expanding copyright primarily benefits content industry distributors (publishers, record labels studios, etc.) rather than authors (Patry 909). They see stronger copyright as harming creative diversity by 
encouraging content industries to focus on a small number of high-budget, heavily marketed "blockbusters" and "superstars" which dominate their market and crowd out more diverse competitors (Nadel 790; Pessach 1091-98). Copyright also favors big content producers and media conglomerates in other ways; they enjoy comparative advantages in clearing copyright conflicts, negotiating cross-licensing deals, and securing preferential enforcement online (Pager, "Making Copyright Work" 1030-32). Such systemic advantages foster industry concentration and discourage market entry (Netanel, "Market Hierarchy" 1917), which may lead to less commercial creativity overall.

Stronger copyright protection can also inhibit creative output directly by impeding secondary creators from building on earlier works or inhibiting the distribution of such works. In a digital age of remix culture, the effects of such "copyright censorship" may be particularly deleterious (Lessig 10-15). Accordingly, copyright's chilling effects on downstream creativity suggest that increased protection may yield diminishing or even decreasing returns (Landes and Posner 332).

Furthermore, even if copyright does lead to more works being created, this does not necessarily guarantee greater diversity. We need to examine what kind of works are created, and perhaps inquire as to the identity of the creators. At this point, the ambiguities in diversity criteria noted above become salient.

The effects of copyright protection on industry concentration and blockbusterization described above serve to concretize the tradeoffs. For those who define diversity primarily based on nationality, copyright's role in sustaining strong national content industries that dominate their domestic markets may represent a feature, not a bug. The high-budget "blockbuster" output such industries generate will compete effectively against foreign (typically U.S. American) imports. And such widely consumed cultural commodities will serve as effective vectors to promote national identity and social cohesion. It is thus no surprise that a country such as France, which values these goals, pioneered the so-called "three strikes" anti-piracy legislation to reinforce copyright norms.

Yet, if one defines diversity based on different criteria, blockbusterization may seem a less satisfactory outcome. Critics accuse the content industries of manufacturing a sterile "commodity culture" conforming to narrowly defined genres that cater to the least common denominator of market demand (MacMillan). They decry the trite formulas recycled by heavily hyped hit songs and cinematic franchises. True innovation-and diversity-invariably comes from outside the system (Pager, "Making Copyright Work" 1037-38). ${ }^{4}$ Moreover, in an age of digital disintermediation marked by a proliferation of creativity from non-traditional 
sources, the copyright system's biases against creative upstarts undermine diversity (Pager, "Making Copyright Work" 1039-40). ${ }^{5}$ Critics also fault content industries for being insufficiently inclusive of women and minorities, arguing that commercial media "neither encompass a wide representative spectrum of viewpoint nor carr[y] the voices of diverse and antagonistic sources" (Netanel, "Market Hierarchy" 1884). ${ }^{6}$

Some argue further that copyright law itself is biased toward the forms of creativity favored by white males to the exclusion of more diverse creators (Craig; Greene), or that it devalues the interests of poor people (Kapczynski 996). Copyright's chilling effect on secondary creation may also disproportionately burden diverse authors who seek to repurpose mainstream media to serve their own expressive aims (Tushnet 133-34). Other commentators question the value of such derivative works, however, arguing that remixes merely reinforce the hegemony of dominant media (Joo 469). Moreover, restrictions on copying may have beneficial effects on diversity by forcing authors to find more original ways to express themselves (Fishman 1336-37).7 Such conflicting perspectives further underscore the extent to which cultural diversity debates turn on subjective notions as to the comparative value of different types of cultural expression.

Copyright markets also exhibit clear inequities as to who benefits: Superstars and industry moguls receive the lion's share of the proceeds, while ordinary creators typically receive only marginal rewards (Towse 107). It is unclear, however, to what extent copyright itself is to blame for such skewed distributions. Arguably, superstar biases and scale economies are inherent features of cultural markets (Shur-Ofry 205-06). Indeed, as will be noted below, there is evidence that such distributional distortions persist under alternative regimes. Moreover, the diversity implications of such distortions remain unclear. So long as the lure of the "copyright lottery" attracts a diverse range of entrants, it may not matter that only a few actually win. ${ }^{8}$

Furthermore, even if ordinary authors do not benefit financially, this does not mean that copyright is irrelevant to them. Copyright still offers transactional efficiencies, promotes creative autonomy, and protects small creators from abuses of corporate power (Pager, "Role of Copyright"; Hughes 933-36; Liu 52029). Copyright also structures the creative ecologies within which diverse creators function in ways that generate both positive and negative spillover effects. As noted above, industry concentration may work against diversity. Yet, the revenues generated by blockbuster culture and the infrastructure it sustains can also crosssubsidize more diverse forms of creativity (Pager, "Beyond Culture vs. Commerce" 96,127 ). For example, many would-be creators find gainful employment in the content industries, honing their talents and acquiring expertise and connections that help them develop their personal projects on the side (Merges). 
Finally, copyright inhibits the diffusion of cultural goods by raising prices and restricting access. Empirical studies have shown that works in the public domain are more widely available than those under copyright (Heald). Even where authors are willing to license their works at reasonable rates, the copyright's system of territorial rights can inhibit their circulation transnationally. For those concerned with diversity of consumption, copyright's restrictions on access to culture may thus be problematic. Copyright's access restrictions may also impair the production of new works by impoverishing the storehouse of cultural resources from which future creators can draw inspiration (Parc and Messerlin 12). Because creativity is its own input, restricting access to diverse sources may thus impair output diversity. Copyright also restricts works from being translated into foreign languages (Shaver), although here the picture is more complex because without copyright incentives, publishers may be reluctant to take on translation projects $(\mathrm{He})$.

Copyright affects cultural translations as well as linguistic ones, whereby existing works are remade and recontextualized for a foreign audience. First, such translations may infringe copyright in the original work directly (Desai). Second, under a rule of international exhaustion, rightholders may attempt to discourage reimportation by engaging in versioning strategies that release multiple versions of a work customized to particular markets. ${ }^{9}$ In either case, how one assesses the diversity implications depends on whether one considers hybridization and glocalization to advance diversity or undermine it (Shim).$^{10}$

It is worth emphasizing that copyright's negative effects can be ameliorated by appropriate tailoring of exceptions and limitations. The idea/expression dichotomy allows abstract ideas, methods, and factual information to be freely copied. Fair use/fair dealing provisions (and their civil law equivalents) similarly shield socially valuable forms of copying. ${ }^{11}$ A shorter term would reduce the deadweight losses from works being "held hostage" in unproductive private rights (Parc and Messerlin 12). Moreover, limits on alienability, reversionary rights provisions, and mandatory benefit-sharing/redistribution can lead to more equitable allocations of copyright's rewards (Pager, "Making Copyright Work" 1044-45). ${ }^{12}$ The extensive literature exploring such tailoring options lies beyond the present scope. Suffice to say that copyright's diversity effects will vary according to its implementation in a particular context. ${ }^{13}$

Furthermore, notwithstanding its demerits, the copyright system still retains significant advantages as a decentralized, market-driven system of cultural production that operates autonomously and largely outside of state control. Indeed, some commentators justify copyright on the basis of democratic speech theory. To the extent that government control is deemed problematic from a diversity 
standpoint, copyright thus offers clear advantages over alternatives such as public patronage (Netanel, "Copyright and a Democratic Civil Society"). ${ }^{14}$

\section{From Theory to Empirics}

Having explored some of the theoretical dimensions along which copyright law may impact cultural diversity, we now turn to an empirical frame of reference. Evidence from real-world outcomes experienced in the film and music industries in recent decades offers further insights on copyright's effects on diversity.

\section{Evidence from Developed Economies}

In general, it is very difficult to analyze copyright's effects empirically. The problem is that legal changes almost never allow for a "control" group that could provide the kind of counter-factual data needed to support confident conclusions regarding the correlation between policy and outcome (Towse 110). ${ }^{15}$ Instead, most empirical studies attempt to take advantage of "natural experiments" using longitudinal data to analyze the impact of policy changes over time. Such studies have produced ambiguous results. For example, a study of U.S. copyright law between 1870 and 2006 examined whether changes in copyright law at different junctures throughout that period had discernible effects on the creation of new works (using copyright registrations as a proxy) ${ }^{16}$ It concluded that changes in copyright law had no uniform, predictable effect on overall creativity. One explanation of this result might be that creative economies are too complex for doctrinal fine-tuning to have much impact (Shur-Ofry, "IP and the Lens of Complexity").

The advent of digital piracy, however, has had a dramatic effect on the de facto strength of copyright protection in recent decades. As such, it has provided the opportunity for a new set of longitudinal outcome studies. Joel Waldfogel has conducted perhaps the most extensive body of research along these lines, relying primarily on data from the U.S. market, which he summarizes in a 2017 paper. The title, "How Digitization Has Created a Golden Age of Music, Movies, Books, and Television" nicely captures Waldfogel's bottom-line conclusion. However, it is worth exploring Waldfogel's findings in detail.

Waldfogel begins by summarizing the now-accepted conclusion of most scholars that digital piracy sharply reduced revenues for recorded music (197). Although the effect of piracy on the film industry has been less severe, here too, its 
downward pressure on revenues is clear. ${ }^{17}$ Waldfogel then traces the countervailing effect of digitization in dramatically reducing the costs to produce and market new works. Even though production costs remain high-and indeed have risen-at the top end of the market a flood of new works from upstart creators has altered the dynamics of film and music industries, which were previously dominated by content oligopolies.

Waldfogel argues that this democratization of content production has undermined the traditional gatekeeping role exercised by the large media firms, allowing a more diverse set of creators to compete for consumer attention. These unconventional entries, which would have been rejected in an earlier era as not commercially viable, can bypass traditional gatekeepers and enter the creative market lottery through the alternative paths enabled by digitization (202). Some of these entries have proven to be surprise hits (209). Consumers thus enjoy a more diverse supply of popular works compared to earlier decades. Waldfogel buttresses his market-driven measures of utility with data regarding the critical reception of new works (204-206). This, too, supports his proclamation of a "golden age" of creative content.

Waldfogel's conclusion that digitization has enriched the quality of creative content is clear. One can also infer gains in cultural diversity from the shift in production and consumption toward the long-tail of creative markets. (Waldfogel's data does not capture output diversity). ${ }^{18}$ However, the role of copyright remains muted in Waldfogel's narrative. Although piracy appears as a background element contributing to the weakening of industry clout, the main emphasis is on the transformative effects of digitization on the supply side.

A similar study, by Glynn Lunney published this year in book form, focuses solely on the music industry. Lunney's title, "Copyright's Excess," telegraphs his normative position plainly. He argues, based on data on the popular music market between 1962 and 1999, that "too much copyright" conferred excess rents on indolent superstar artists, leading them to produce fewer works and of lower quality (4-5). ${ }^{19}$ Lunney attributes a rise in music supply and quality since then to the weakening of copyright due to unauthorized online filesharing starting with Napster in 1999 (8-10). He concludes with a call for further reforms to reduce copyright.

It should be noted that Lunney and Waldfogel's parsing of the data on music quality is not beyond question. For example, Stan Liebowitz has suggested that a "generational cohort" effect may explain fluctuations in perceived music quality. ${ }^{20}$ In addition, a more limited 2017 study by Danaher and Smith exploring the effect of file sharing on the film industry found some evidence suggesting that piracy had affected country-level film production. They found that countries in which piracy 
had a greater impact produced fewer Academy Awards films compared to the prior decade (934-37). Finally, Waldfogel's findings suggesting that creative markets have shifted toward the long-tail stands at odds with Anita Elberse's assessment that " $[\mathrm{r}]$ ather than undermine the role of blockbusters and superstars, digitization [has] fuel[ed] a winner-take-all trend," leading to "more-not less-concentration in markets for entertainment goods" (199).

It is beyond the present scope to reconcile these conflicting analyses. However, Elberse's findings regarding "blockbusterization" do complement Waldfogel's digital democratization narrative in one respect: Elberse explains the former as a response to the latter. She describes how the proliferation of digital content has made it necessary for big media firms to supersize their own production and marketing budgets to ensure that their offerings make a big enough splash to grab public attention (229). Accordingly, creative content markets may be moving in more than one direction.

It is also notable that Elberse attributes the growing emphasis that Big Media firms place on developing blockbuster/superstar culture as, in part, a reaction to piracy. She explains that such "tentpole"/franchise strategies represent a push to develop alternative revenue streams through merchandising and branding that are less vulnerable to piracy (Elberse 236-41). If so, we might expect smaller competitors and lower profile, long-tail works to be disadvantaged in this contest. This point will be further explored below.

Nonetheless, a clear takeaway regarding the effects of piracy (and thus copyright) on cultural diversity in developed markets remains elusive. Lunney's diagnosis of "excess copyright" does have some support in theoretical literature. Most economists, for example, agree that copyright lasts too long (Towse 105). Legal scholars are also generally skeptical of copyright's expanding scope on efficiency grounds. However, even if we agree that too much copyright is undesirable, that does not mean that we would be better off eliminating copyright entirely. To understand what cultural diversity would look like in the absence of copyright, we can look to two sorts of evidence: (a) historical studies that examine the effect of introducing copyright protection; (b) conditions in markets where piracy is far more pervasive-namely, the developing world.

\section{Historical Evidence}

The leading study of the effects of introducing copyright on creative production is Michela Giorcelli and Petra Moser's analysis of opera composers in Napoleonic Italy. Their study analyzes the effect of extending copyright protection on creative output. It exploits the fact that different Italian states adopted copyright laws at 
different times, thus furnishing the basis for a natural experiment. Giorcelli and Moser find a significant increase in the number of new operas premiered in Italian states that adopted copyright as compared to Italian states that did not. They also found that copyright affected the quality of the works. The number of high-quality operas produced in copyright-protecting states increased, as measured both by contemporary popularity and by durability (specifically, whether the works are available on Amazon today).

Giorcelli and Moser's findings are consistent with the notion that copyright incentives lead to greater investment in creative production. They are buttressed by anecdotal evidence from leading composers such as Rossini and Verdi supporting the idea that the increased revenues provided from performance rights encouraged these composers to invest greater efforts in making memorable works that would be widely performed (2-3). Thus, Giorcelli and Moser offer a convincing endorsement of copyright law as a driver of artistic production. To the extent that cultural diversity is linked to the quality and quantity of output, their study has important implications for contemporary debate.

However, Giorcelli and Moser offer an important caveat: while introducing copyright had positive effects on creativity, increasing copyright through longer terms of protection had no such effect and, in some cases, correlated with reduced output (3). In sum, Giorcelli and Moser's work is consistent with the notion that moderate copyright protection is conducive to cultural diversity, but "excess copyright" may undermine it.

From this historical perspective, we turn now to contemporary evidence from developing countries: examining creative industries in India, China, and Nigeria. If Giorcelli and Moser highlight the positive effects of copyright, these case studies point to the flip side of the coin: the deleterious effects on cultural diversity in countries where piracy is rife.

\section{Evidence from Developing Economies}

i. India

As it happens, Waldfogel has also co-authored a notable study in this context with Rahul Telang. They examined the effects on India's film industry in the late 1980 os and early 1990 s caused by the spread of home video technologies and independent cable television operators. These served as conduits for pirate distribution and allowed consumers to watch home movies for free, including films 
currently playing in the cinema. Such illicit competition reduced Bollywood's per movie revenues by as much as 50\% (Telang and Waldfogel 19).

Reduced revenues, in turn, led to fewer movies being produced (21). In notable contrast to Waldfogel's findings in the U.S. context, Telang and Waldfogel further conclude that the quality of Indian films produced in this period also declined (22). These contrasting findings are instructive because the effects studied in the Indian context largely precede film digitization. Accordingly, they measure the harm caused by piracy directly, without any offsetting complications due to efficiency gains that digitization coterminously enabled. ${ }^{21}$

Telang and Waldfogel further document a revival in Bollywood production after 20oo, leading to more and higher quality films. They attribute the turnaround, in part, to stepped up copyright enforcement that curbed the threat from pirate cable channels (12). ${ }^{22}$ While Telang and Waldfogel do not analyze film diversity per se, this later period has been associated elsewhere with a more diverse range of Indian film production (Pager, "Beyond Culture vs. Commerce" 118-19).

Digital piracy has had similarly harmful effects on the Indian music industry, decimating legitimate sales channels and severely impairing the diversity of recorded music in the market. The Indian music industry has historically functioned as an adjunct to film production (Booth 263,67). Most of the popular films feature extended musical segments and rely on catchy new music to help market the movie (Liang and Sundaram 388). Toward the end of the $20^{\text {th }}$ century, however, industry players began to view recorded music as an independent revenue source, worthy of investment in its own right. Producers diversified into genres other than film music, recorded music in languages other than Hindi, and extended distribution into nontraditional markets (Booth 267). The advent of digital piracy abruptly reversed these trends, causing revenues to collapse. As the industry scaled back production sharply, language and genre diversity suffered, and the production of recorded music largely reverted to its prior diminished status as a loss-leading investment designed to sell film tickets (Booth 270-72, 280-81).

\section{ii. China}

The dystopian effects of piracy on cultural diversity are also visible in China. The Chinese music industry experienced a massive drop in revenues from roughly 2003 onward as online filesharing of pirated music rapidly displaced legitimate sales. At a time when Chinese spending on entertainment and leisure was steadily rising, revenue from recorded music dropped by more than half (Priest 476). As investment in new music production collapsed, the Chinese music market became increasingly dominated by imported music from neighboring countries (Liu, "Tough Reality of 
Piracy" 658-59). Chinese musicians, for their part, sought to record music either for export markets which offered a more secure source of revenues, or to cater to the growing demand for mobile phone callback ring-tones, a solitary island of domestic music sales insulated from piracy (Liu, "Copyright for Blockheads" 481). Industry revenues have rebounded in the past few years as online intermediaries have entered into licensing deals and largely weaned themselves off pirated content. However, China's music industry remains comparatively undeveloped for a country of its size and affluence (Liu, "Copyright for Blockheads" 474-75).

On its face, China's film industry has weathered the effects of piracy more successfully due to expanding markets for theatrical distribution. However, independent movies are denied access to state-regulated cinemas, restricting the diversity of movies that benefits from theatrical revenues (Priest 493). Instead, Chinese indie films depend on online distribution, and, until recently, revenues from online distribution were undermined by pervasive piracy (Priest 486). However, the leading internet streaming platforms have recently purged their websites of unauthorized content and embraced copyright compliance norms (Montgomery and Priest 348). As the leading streaming platforms compete for exclusive rights to audiovisual content, domestic licensing fees have soared, spurring investment in high quality content. This has provided much-needed revenue for independent films in particular (Montgomery and Priest 348-49). In both these regards, copyright has arguably served to facilitate cultural diversity, just as piracy undermined it.

\section{iii. Nigeria and Piracy's Promise}

Piracy's effect on cultural diversity is not always negative. Pirate networks are often adept at pioneering markets, exploiting new technologies, and evading censorship and trade barriers. Unauthorized distribution serves as a form of marketing that indirectly generates revenues for creators and often later matures into a direct revenue source as pirates formalize their operations through licensing (Athique 705-06, 712-13).

Piracy's benefits are not limited to distribution. By exposing budding local artists to foreign media that are otherwise hard to access (due to prohibitive pricing or import restrictions), piracy can both promote media literacy and inspire future creativity (Parc, Messerlin, and Moon 141). Moreover, pirate operators sometimes move into content production in their own right. The Indian and Chinese content industries offer several examples of pirate production that led to formalization thereafter (Athique 712-13; Montgomery and Priest 348-49).

However, the archetypal example of an entirely new creative industry built on pirate networks and still largely dominated by informal business practices is 
Nigeria's "Nollywood." In less than two decades, Nigeria went from producing an average of three films per year in the 1980s and early 1990s to producing roughly a thousand movies annually in the years since 2000 (Pager, "Folklore 2.0" 1853). Nollywood videos are distributed all over Africa and beyond and have become a daily presence in the lives of millions. Nollywood's success has, in turn, inspired imitation by digital film industries elsewhere in Africa. By empowering African voices to tell African stories, such industries have contributed greatly to cultural diversity (Pager, "Folklore 2.0" 1855-58).

In recent years, Nigerian filmmakers and policy-leaders have pushed for Nollywood to formalize its operations and adhere to global copyright norms. Yet, the industry remains dominated by marketers' guilds who operate through informal networks and generally ignore copyright formalities (Miller 47, 54-59). Nollywood's success, and the success of other creative industries that operate under similarly informal business norms, have attracted the attention of copyright skeptics. The ability of such diverse industries to thrive in the absence of copyright is taken as proof that copyright is obsolete. Skeptics argue that the alternative business models pioneered by such industries demonstrate the feasibility of commonsbased production, which offers clear normative advantages over copyright. We address these issues next.

\section{CONSIDERING ALTERNATIVES: COMMONS-BASED PRODUCTION \& CULTURAL DIVERSITY}

Digital tools make content production cheap and easy and enable global distribution costlessly at the click of mouse. Measured by sheer output, the results are undeniably impressive. The petabytes of expressive content posted every day to online platforms such as YouTube, Flickr, Facebook, and Instagram furnish no end of gaudy statistics. Moreover, there is ample evidence that the internet has diversified the range of expression and viewpoints in cultural circulation. Digital creativity encompasses a wide array of formats and genres from blogs and wikis to mash-ups, remixes, machinima, and vines. Minority voices, subcultures, and specialty interest groups have all found outlets to assert their distinctive identities and forge communal ties with likeminded others.

Much of this bottomless upwelling of "user-generated content" (UGC) is prompted by non-economic motives. Commentators have hailed the rebirth of a digitally enabled folk culture (Benkler, Wealth of Networks 15), the advent of a post-scarcity society (Lemley), and even a "New Enlightenment" (Sunder 276). Given this democratization of creativity, commentators question the need to 
continue subsidizing cultural production via copyright (Moglen). Moreover, as digital creativity often entails remixes and mash-ups of existing works, the specter of copyright infringement casts a chilling shadow (Lessig 18). Instead of a driver of creativity, copyright is lambasted as a vehicle for corporate rent-seeking and censorship. Does this mean that copyright is no longer worth the candle?

\section{A. The Limitations of Amateur Creativity}

On the other hand, relying on commons-based production to drive cultural innovation in lieu of copyright has important limitations and drawbacks from a cultural diversity standpoint. First, non-commercial creativity by amateurs necessarily operates within a spectrum of bounded capabilities. To undertake creative projects of scale and ambition requires investments of time and resources that lie beyond the reach of hobbyists. While amateur work can be genuinely creative and worthy of admiration, the level of authorship invested in any given work is typically low. Amateurs generally restrict themselves to short-form content involving modest production values, often piggybacking on preexisting works through mash-ups and remixes or building on well-established memes and templates. The result is an endless array of pet videos, memes, and snarky commentary, but very little that can rival commercially-produced content in scope, sophistication, or production values (Keen, 2007). ${ }^{23}$ Such creativity may well be diverse on its own term, but its limited scope and creative ambitions are problematic. $^{24}$

Diversity concerns also arise from unequal opportunities to engage in digital creativity. A certain technical sophistication is required to engage in many forms of digital production, which favors those with technical aptitude. It also helps to have ample leisure time. The digital divide privileges digital natives over earlier generations, men over women, and wealthy elites over the poor and disadvantaged minorities (Brake; Chon845-46), all of which implies troubling inequalities of access that could impair diversity. Indeed, given the frequency with which cultural innovation and diversity have emerged from marginalized elements of society (Pager, "Folklore 2.0" 1881-82), such discrimination is doubly troubling.

In some cases, individual contributors can overcome the limitations of amateur creativity by collaborating with others. The internet enables creative projects to leverage contributions from diverse, decentralized communities online (Benkler, "Coase's Penguin"). However, such "peer production" requires the ability to split creative projects into discrete, modular tasks whose separate outputs can be reassembled and integrated without undue coordination costs. This works well for 
functional and informational projects such as open source software and Wikipedia. Yet, peer production is ill-suited to aesthetic works that entail intensive, coordinated acts of authorship. Writing a novel, producing a narrative film, or composing a symphony cannot feasibly be delegated to a dispersed committee operating based on asynchronous, parallel production. Instead, would-be authors need to invest concentrated time and effort to create such works. And such authors generally expect to be paid.

\section{B. Are Alternative Business Models a Substitute for Copyright?}

Even if authors require compensation, however, this does not mean that their funding source must necessarily derive from copyright. Commentators have pointed to a wide range of alternative business models that are allegedly compatible with commons-based (aka. "open") distribution. ${ }^{25}$ Some are quite traditional, others entail cutting-edge internet-enabled innovation. Would adhering to such alternative models yield greater cultural diversity than copyright?

There are reasons to be skeptical. As will be discussed below, alternative models work well for some types of content in certain contexts, but not others. The level of funding realized is often meager. And they often come with hidden drawbacks and limitations that constrain diversity of output. We address these issues in turn.

\section{Inadequate Revenues}

Nigeria's success in building Nollywood into a global film industry is nothing short of miraculous. However, funding remains its Achilles heel. Relying on lead time and informal distribution, norms to stay one step ahead of piracy puts an upper bound on revenues (Miller 48,53-54). ${ }^{26}$ As a result, filmmakers make minimal investments in any single project and instead have adopted a "spawn" instead of "nurture" strategy that releases a steady flood of creative progeny into the market in the hope of evading pirate predation through sheer numbers.

Nollywood is certainly diverse on many levels. Each of Nigeria's major ethnic groups has its own regional film industry that produces movies in a different language (Miller 3). Nollywood movies also exhibit diversity of genre, subject-matter, and viewpoint. The people who make them are also diverse. Multi-ethnic casts and crews are common, and a significant number of Nollywood directors are female (McCall 81 ). Yet, the diversity of content is notably shallow: Nollywood movies recycle 
familiar elements within well-defined genres based on established formulas. Without the resources to invest in product differentiation strategies or marketing, Nollywood emphasizes standardized products that offer predictable customer appeal (Lobato $25,57)$. In short, revenue shortfalls due to the absence of copyright have encouraged commoditized culture. Too little copyright may be just as bad as too much.

Music generally costs less to produce than film. As such, resource constraints may be less prohibitive. Even so, it is notable that successful "open" music industries often involve remix genres that operate on the low-cost end of the spectrum (see Santos 603-633).

\section{Limited Applicability}

Open music industries distribute free recordings to promote concerts. In other words, the "copy" is paid for through performance revenues. Yet, performance models have significant limitations. Far fewer people are willing to pay to hear a writer read her book aloud or a photographer narrate a slide show.

Even in the realm of music, not all genres lend themselves to live performances equally well. In general, acts that involvelive spectacles, with elaborate choreography, lights, and costume changes do well. Korean K-pop bands thrive on this model (Seabrook), but not all musicians are natural performers; some are stage shy; others may not want to endure the rigors of long road-trips (e.g. parents of young children). Artists with widely dispersed fan bases may struggle to fill venues in any one location. And in some countries (e.g. China), public performance venues are in short supply or are subject to censorship (Liu 486). ${ }^{27}$ Thus, relying solely on a concert model to fund professional musicians could limit the diversity of music thereby supported. For example, music recorded for children (e.g. lullabies) would likely have limited revenue prospects on a concert tour. In some contexts, the nature of the performance itself constrains diversity. For example, Egyptian musicians earn most of their revenue performing at weddings (Rizk 350). Needless to say, such engagements demand specific genres of music (romantic ballads) at the expense of others (e.g. protest songs).

\section{Selection Biases}

This concern about selection biases can be generalized to a larger point about proxies. Most alternative business models seek to fund one type of creative 
production (producing the work) by tapping a complementary revenue stream. Musicians give away recorded CDs to promote concert sales. Open-source software firms hope to win servicing contracts for the code they distribute freely. However, such proxies are rarely perfect substitutes. When cultural innovation becomes divorced from its true stakeholders, it becomes hostage to the vagaries of whatever the alternative market is presented with the bill. Sponsors may turn into censors, fake news may prevail over real news, and content everywhere will succeed less on the basis of intrinsic quality than on its compatibility with Happy Meal figurines, or other similarly perverse selection criteria.

Indeed, some sponsored Nigerian films already resemble thinly disguised infomercials (Pager, "Accentuating" 272). Critics of advertising-supported media see similar distortions at play warping content to suit preferred demographics and promote consumerism (Baker 25-30; Strandburg 97). The example of Indian music, mentioned above, offers a further example: Subservience to the film industry has restricted diversity. When Indian musicians could earn money from selling recordings directly, they catered to markets that otherwise went untapped (Booth, 267-70). Chinese musicians aiming to license callback ringtones are similarly inhibited: Short, ear-catching melodies are favored in this market over more sophisticated compositions (Liu, "Copyright for Blockheads" 481).

Online platforms that rely on digital advertising models, for example, place a premium on provoking user engagement, which favors content that stimulates outrage or stakes out extreme positions. More generally, the surfeit of content competing for online eyeballs encourages manipulative tactics: exploiting attention-getting headlines (click-bait) or curiosity-provoking formats (listicles). In some cases (e.g. internet quizzes), the content is driven by ulterior objectives: namely, extraction of personal data. The result has been an internet populated by superficial fluff and fake news-hardly the paragon of cultural diversity that cyberspace was held out to be, as a chorus of recent recriminations from within Silicon Valley itself has acknowledged (Kulwin).

By contrast, properly functioning copyright regimes allow creators to internalize benefits from a much broader spectrum of market demand. In theory, matching revenues to consumptive demand should lead to cultural production that is more responsive to societal needs. ${ }^{28}$ Indeed, some commentators justify the breadth of copyright's derivative works right precisely to encourage authors and publishers to respond to market signals across the full gamut of potential audiences and users (Goldstein). 


\section{Alternative Control Mechanisms and Abuse}

Not all "alternative" revenue models are necessarily compatible with open distribution. For example, although theatrical film exhibitions superficially resemble the performance model for music, film studios are hardly about to release copies of their films as a promotion gambit. Few people would pay to watch something at the Cineplex that they can watch for free at home. The film industry therefore relies both on copyright to suppress pirate copies from circulating and on physical control over access to their content.

The latter tactic-using physical control to prevent unauthorized access-is characteristic of other "alternative" models that employ exclusionary strategies to preserve de facto exclusivity. Such restricted access diverges sharply from the unconstrained free flow of content that commons enthusiasts contemplate. Instead, denied access to copyright, the response of content producers is often to replicate equivalent restrictions through alternative means.

Such restrictions can impair cultural diversity and are prone to abuse. For example, distribution of Nollywood videos in Nigeria is controlled by marketers' guilds who enforce exclusivity norms through informal control over local markets, often backed by threat of violence. Such guilds are typically ethnically-based and privilege relationships with in-group members over outsiders (Miller 45-46). Abuses of power and favoritism are not uncommon. Yet, guilds have a stranglehold that preempts alternative distribution regimes and perpetuates Nollywood's underdeveloped condition (Bud).

Commentators perceive similar abuses in the online content market, which is controlled by a handful of dominant platforms that enjoy entrenched positions due to network effects (Pessach, "Beyond IP"). The risk of competitive abuses and preferential treatment grows more salient as technology titans in the United States and China move into producing their own content. Big media firms can leverage favorable terms in return for access to their copyrighted portfolios. Yet, independent creators are vulnerable to exploitation, which could impair cultural diversity.

In the Chinese music industry, a different sort of control underpins revenues: technology. The recorded music industry has relied heavily on sales of ring-back tones for mobile telephones. These musical snippets, which callers hear while awaiting an answer to their call, are stored on the centralized architecture of the phone company, which prevents the use of unauthorized copies. ${ }^{29}$ As such, until recently, they supplied virtually the sole revenue source for an industry ravaged by piracy. Yet, lacking alternatives, music producers have been held hostage to China's 
mobile phone duopoly, which usurps over $97 \%$ of the revenue generated, leaving musicians and labels starved for funding (Priest 502).

More generally, digital rights management and other access-restricting technologies are widely used to control copying of digital works in other contexts (Hughes, "Motion Pictures" 953-57). Such technologies invariably impose more restrictive limits than copyright law would allow (Jacques, et al., 29). As such, they prevent creative reuse by secondary creators, as well as restrict access generally in ways that impair cultural diversity. In the absence of copyright, one could expect the use of such technologies to expand.

\section{IMPLICATIONS AND RECOMMENDATIONS}

To summarize, digital technologies have democratized and diversified creativity. The proliferation of amateur creativity and increasing reliance on alternative business models has led some commentators to question the need for copyright. Yet, while these alternative models work well for some creators, they have significant drawbacks and limitations that limit the diversity of content that can be supported.

Copyright has its own drawbacks. However, it does allow authors and publishers flexibility to pursue diverse monetization options as well as the leverage to negotiate favorable terms with intermediaries. Moreover, the empirical evidence reviewed in Part I-C, while ambiguous, can be read as suggesting that having either too much copyright or too little copyright can be detrimental to diversity. On balance, it thus seems prudent to keep a modestly tailored copyright regime as part of the mix of options. Producers can still choose open distribution, or they can mix open and proprietary models to suit their particular needs. There are many kinds of creativity, and no one-size-fits-all formula is likely to prove satisfactory. However, when properly tailored with appropriate exceptions and limitations, copyright law can be a net contributor to cultural diversity.

How to tailor copyright for diversity presents a larger topic than can be usefully addressed in the space available here. However, it may be worth briefly sketching out some prescriptions framed from the standpoint of at least one important source of cultural diversity, namely, the emerging breed of "creative upstarts" who produce commercial content outside the ambit of the mainstream content industries..$^{30}$

The digital age has led to a proliferation of commercially-minded creators who operate in non-traditional spaces. ${ }^{31}$ Such creative upstarts comprise a diverse group who include self-published authors, independent musicians, filmmakers, graphic 
artists, photographers, bloggers, podcasters, YouTubers, DJs, mash-up artists and remixers, mobile app designers, as well as creative entrepreneurs in many other niches. Collectively, creative upstarts make a vital contribution to cultural diversity, filling important gaps between amateur and professional creativity. As mainstream content industries focus myopically on catering to the least common denominator of mass market demand, upstart creators often target neglected niche audiences and supply novel perspectives and creative visions. Where blockbuster culture recycles tired formulas, upstarts can afford to take more chances artistically and introduce creative innovations that leave lasting impacts (Pessach 1090-91). Unlike amateur creators, however, upstarts are in it for the long haul; they are willing to invest greater time and resources honing their craft and are therefore capable of more sophisticated productions than amateurs (Pager, "Making Copyright Work" 1036-39).

The contribution that creative upstarts make to cultural diversity therefore merits consideration in framing copyright policy from a diversity standpoint. Yet, their needs have been neglected both in copyright discourse and in practice. Modern copyright systems were not designed with the needs of creative upstarts in mind and function in ways that systematically disadvantage this important constituency. ${ }^{32}$ In particular, the complexities of both substantive copyright law and its surrounding institutions impose undue hardships on those who lack the knowledge and capabilities to navigate them effectively. Unable to afford legal advice, upstart creators often fail to act proactively to secure their rights and circumvent the rights of others, which can limit their creative and commercial potential. ${ }^{33}$ As such, copyright fails to serve the interests of this important constituency. As ever more upstart creators venture into the brave new world of digital disintermediation, such problems redound to the detriment of cultural diversity.

Reforms aimed at remedying such inequities must accordingly focus on reducing information and transaction costs throughout the copyright system. Instead of debating "more copyright" vs. "less," a creative upstart perspective would focus on making the system simpler, more accessible, and less expensive to use. In terms of substantive law, a priority would be to supply greater certainty to upstart creators by enacting clearer rules, guidelines, and safe harbors..$^{34}$ Reducing barriers to transnational distribution/licensing would also afford upstarts greater access to regional/global markets (Ranaivoson 686).

The bulk of reform efforts, however, should arguably focus on reinventing institutional aspects of the copyright system to reduce barriers to access. Providing low-cost solutions to resolve small claims and more effective tools to police online infringement would mitigate enforcement burdens (Pager, "Making Copyright Work" 1046-47). Partial reformalization, coupled with improved registration systems would make clearing copyright more feasible (Gervais and Renaud; 
Samuelson 1200-05). There is also a case for more aggressive scrutiny of practices by collecting societies and online intermediaries that discriminate against upstarts (Pager, "Making Copyright Work" 1049-50).

Investments in capacity-building can make copyright regimes more user friendly by educating and empowering creative upstarts to navigate the enduring complexities of the system more effectively. Technology has a vital role to play here. Low-cost, internet-enabled platforms can help creators secure their own rights, clear the rights of others, and engage in commercial transactions to disseminate their content. Examples of promising technological initiatives currently under development include computerized expert systems to advise authors (Pager, "Making Copyright Work" 1051-52), metadata standards to ensure database interoperability between copyright registries and collecting societies (Internet Policy Task Force 94-87), the use of blockchain technologies for digital rights management and licensing (Willms; Fabian), and other automated microlicensing/payment systems (Internet Policy Task Force 96). Broader investment in developing such tools could yield lasting dividends in promoting cultural diversity.

\section{CONCLUSION}

The connections between copyright and cultural diversity are complex and multidimensional, and ambiguities as to the concept of diversity further obfuscate the debate. There is significant disagreement as to copyright's effect on diversity, and the results may depend on the context. Indeed, copyright levels may be suboptimal from a diversity standpoint in developing countries and superoptimal in developed economies.

However, on balance, appropriately tailored copyright regimes remain a positive force in contributing to cultural diversity. Future policy attention should be directed, however, to minimizing the transaction costs required to navigate the copyright system. Digitally disintermediated "creative upstarts" comprise an important constituency from a diversity standpoint. Their emergence demands greater emphasis on ensuring that the institutions of the copyright system (both public and private) remain accessible and non-discriminatory. New technologies can also reduce barriers and empower upstart creativity. Adopting such reforms and capacity-building measures would redound to the benefit of cultural diversity. 


\section{Notes}

1. Given today's Web 2.o read-write technologies, some would argue for even more ambitious measures of audience participation in cultural meaning-making (Sunder 276-80).

2. In the E.U. context, recent scholarly attention has explored the copyright-diversity nexus within the specific context of collecting societies and cross-border licensing (Ranaivoson, Iglesias, and Vondracek).

3. Glynn Lunney challenges this claim in a recent book on music copyright, arguing that showering wealth on superstar artists leads them to become less productive both qualitatively and quantitatively, see infra Part I-C.

4. The New Yorker drove this point home in a 2012 article about Korea's K-pop music industry. Often described as an archetype of "factory culture," K-pop's industry sponsors employ sophisticated management training techniques to package aspiring "idols" into carefully crafted pop groups, which are then rigorously trained, groomed, and choreographed for years by industry consultants to prepare them for future stardom. The New Yorker noted, however, that K-pop's most famous international star, PSY, "has never been idol material" and achieved his breakthrough hit, "Gangnam Style," "by satirizing standard K-pop tropes." It concluded by observing that the fact "that a pudgy guy with a goofy dance can succeed where the most brilliantly engineered idol groups have not suggested that cultural technology can get you only so far" (Seabrook).

5. Most scholars emphasize digital empowerment of non-commercial creativity, as will be discussed below in Part II. However, digitization has also led to an explosion of commercial creativity from non-traditional sources, whose collective efforts arguably make an important contribution to cultural diversity. The needs of this latter constituency have arguably been neglected in copyright policy debates. This latter point will be explored in Part III.

6. Such diversity biases may also compound over time as consumers are influenced by the range of cultural choices they encounter in the market, as well as the consumptive choices made by their peers. As such, a less diverse supply of cultural offerings could, in turn, distort consumer demand toward mainstream tastes (Baker).

7. Copyright's effects in this regard remain controversial. Rebecca Tushnet argues that "it's too simple to say that ' $[\mathrm{w}]$ ithout a derivative work right, we may get more homogenization."' (130). She contends that "creativity is too varied to conclude that copyright's constraints are useful." (128). In this regard, it is worth noting a nascent theoretical literature that attempts to model copyright's effects on product differentiation directly (Bracha and Syed; Abramowicz; Yoo). Contrary to the conventional agnosticism of copyright doctrine, such scholarship recognizes that the sheer number of works produced may matter less in terms of satisfying societal demand than the spacing of such works across the demand spectrum and seeks to apply these insights to optimize copyright doctrine. The implications 
of this product differentiation literature for the larger debate on copyright and diversity remain unclear, however, and arguably merit further exploration.

8. The real question is whether copyright markets function as an efficient sorting mechanism to reward socially valuable creativity. This begs further questions as to how to define and measure the social value of creativity, itself a contested debate that extends beyond the present scope.

9. An international exhaustion rule allows a copy of a work that is lawfully purchased anywhere in the world to be freely resold without infringing copyright. By contrast, national exhaustion rules limit resale rights to purchases made within the national territory, thereby preventing parallel imports of grey market goods (Gautam). There is anecdotal evidence that such versioning strategies have increased in the wake of the 2013 Kirtsaeng decision, which moved the United States to an international exhaustion rule.

10. The analysis is complicated because the likely effects register along different axes: Hybridization reduces transcultural diversity while it arguably increases global diversity (Cowen 15).

11. A plethora of proposals seeks to ratchet back copyright in various ways to allow greater room for secondary creativity based on preexisting work. The normative desirability of such reforms depends, in part, on how one values the diversity contribution made, for example, by fan fiction and other forms of remix art. As Part II notes, such amateur creativity is diverse on many levels, but often limited in scope and sophistication. Moreover, the extent to which copyright serves as a barrier to such creative pathways remains contested. In general, there is already a fairly broad tolerance of non-commercial secondary creativity in practice, if not squarely established in law (Lee 1462).

12. Competition law and communications/media regulations are highly relevant here as well (Benkler, "Wealth of Networks" 399-410, 435).

13. Furthermore, the information and transaction costs entailed in navigating the copyright system can also affect diversity. This point will be explored further in Part III.

14. In theory, patronage offers advantages over copyright by awarding funding based on artistic merit, rather than commercial appeal and avoiding deadweight losses to exclusivity. However, in practice, patronage regimes suffer from endemic inefficiencies that blunt their appeal (Pager, "Beyond Culture vs. Commerce"). Nonetheless, they arguably play a role in filling gaps that copyright markets neglect such as avant-garde works or social engagement.

15. For an innovative proposal to deliberately incorporate experimentalism into intellectual property reforms, see Ouellette.

16. Up until 1988, copyright formalities were mandatory prerequisites for U.S. copyright. Thus, new works motivated by copyright incentives would have been registered. After 1988, formalities were no longer mandatory. However, incentives for timely registration remain. 
17. For example, DVD/VHS sales fell $27 \%$ in the four years after the widespread adoption of the BitTorrent protocol 2004 despite having risen from 2000 to 2003 (Danaher, et al.).

18. In a companion paper focused solely on the film industry, Waldfogel does present some limited data on genre diversity that is generally consistent with his overall positive narrative ("Cinematic Explosion" 762).

19. Lunney thus directly contradicts Merges' thesis about creative autonomy yielding fewer works of higher quality, which was itself based partly on empirical findings about the effect on introducing music composition copyrights in the $19^{\text {th }}$ century (Merges 1264-66).

20. The idea is that people generally favor the music they grew up with. Thus, the larger the generational cohort, the more popular the music. Millennials, the generation that has come of age in the filesharing era, have recently passed Baby Boomers as the single largest tranche of the U.S. population. Thus, "their music" would be expected to measure favorably in surveys, followed closely by Boomer-era music. By contrast, the music of smaller, intervening generations would be expected to register comparatively poorly on this basis.

21. Similar accounts have been made of piracy's harmful effects on film industries in the Philippines (Whaley) and Mexico (Ch'oe).

22. Other factors also contributed to the industry's improving outlook, including the growth of multiplex theaters, television licensing, and overseas revenues. While these factors are not directly tied to copyright enforcement, it should be noted that all of these revenue streams depend, to some degree, on copyright exclusivity to function effectively. Most people do not watch a movie more than once, and it is hard to get customers to pay for something that is available for free, underscoring the importance of suppressing unauthorized distribution.

23. Consumers reveal the comparative value they assign to professional content by their willingness to pay for it: Despite having access to a vast ocean of free content, they continue to fork over hefty fees every month for commercial subscriptions to premium cable channels, Netflix, Hulu, Spotify, and similar services (Manjoo). The most popular content on free online platforms such as YouTube is also invariably professionally produced.

24. It is as if all poetry were limited to the length of a haiku. No matter how diverse the range of expression thereby rendered, one would feel that poetry as a whole has been impoverished.

25. Definitions of commons-based or open distribution vary, but generally contemplate foregoing or substantially paring back copyright restrictions, thereby alleviating the deadweight losses associated with exclusive rights. However, the extent to which such models are compatible with a world in which copyright was abolished entirely remains an open question (Liu). In many cases, residual anti-copying norms remain a background assumption. In the case of open source licensing, copyright exclusivity is explicitly leveraged as a safeguard against private appropriation. 
26. Nollywood filmmakers also employ sponsorship deals and product placement to raise additional funds. But Nigeria lacks a strong consumer culture, and the total revenues that can be generated from these sources are limited.

27. Other restrictions can also limit the scope for performance models: for example, countries with unsafe cities or decentralized rural populations will struggle to fill concert halls, and women are denied access to the public sphere in many Muslim countries (Pager, "Accentuating the Positive," 269-70).

28. Distributional biases remain salient, however: Copyright markets only respond to those who have the means to patronize them (Kapczynski 996).

29. Mobile phone users pay a small monthly fee to the phone company to select personalized music. Such musical snippets are extremely popular in China, generating US $\$ 4$ billion in annual revenue (Priest 502). Ring-back tones are also popular in Nigeria, accounting for an estimated US $\$ 150$ million market there.

30. This section draws on prior work by the present author (Pager, "Making Copyright Work for Creative Upstarts"). An extended version of the argument containing far greater detail can be found there.

31. Creative upstarts exemplify the phenomenon of digital disintermediation in the creationand distribution of commercialcontent. Yet, while digitaldisintermediation itself has been widely chronicled, the entrepreneurial communities operating within its rubric (creative upstarts) remain underexamined, as do the policy implications they pose for both copyright and cultural diversity.

32. The copyright system was largely fashioned in an earlier era when the production and distribution of commercial content required large capital-intensive enterprises. Such enterprises could afford legal counsel to guide their operations and implement administrative systems to secure and transact rights effectively. The laws and institutions that have emerged cater to such sophisticated operators and effectively take their capabilities for granted (Pager, "Making Copyright Work" 1033-34).

33. This problem applies even to creative upstarts who rely on alternative business models insofar as they are exposed to infringement claims from third-party copyrights (and incur costs in clearing such rights). Infringement threatens amateur creators, too. However, non-commercial creativity often flies beneath the radar or is tolerated by rightholders as fair use (either de facto or de jure). As commercial entities, creative upstarts are much more exposed to the threat of enforcement.

34. There are limitations to this approach. In a world of fast-changing technologies and business practices, clear-cut rules quickly become blurred, or-worsemisdirected. Instead, a more realistic fallback goal may be to couple open-ended standards with clear safe harbor provisions or explicit examples. This way, the standards would have room to evolve, but at least their core meaning would be anchored (Pager, "Making Copyright Work" 1044). As a further backdrop, guidelines reflecting "best practices" offer guidance 


\section{Works Cited}

Abramowicz, Michael. "A New Uneasy Case for Copyright." George Washington Law Review, vol. 79, 2011, pp. 1644-91.

Athique, Adrian. "The Global Dynamics of Indian Media Piracy: Export Markets, Playback Media and the Informal Economy." Media, Culture E Society, vol. 30, no. 5, 2008, pp. 699-717.

Baker, C. Edwin. Media, Markets, and Democracy. Cambridge UP, 2002.

Benkler, Yochai. "Coase's Penguin, or, Linux and the Nature of the Firm." Yale Law Journal, vol. 112, 2001, pp. 369-446.

--. The Wealth of Networks: How Social Production Transforms Markets and Freedom. Yale UP, 2006.

Boldrin, Michele, and David K. Levine. Against Intellectual Monopoly. Cambridge UP, 2008.

Booth, Gregory. "Copyright Law and the Changing Economic Value of Popular Music in India." Ethnomusicology, vol. 59, no. 2, 2015, pp. 262-87.

Bracha, Oren, and Talha Syed. "Beyond the Incentive - Access Paradigm? Product Differentiation \& Copyright Revisited." Texas Law Review, vol. 92, 2014, pp. 1841-1920.

Brake, David R. "Are We All Online Content Creators Now? Web 2.o and Digital Divide." Journal of Computer-Mediated Communications, vol. 19, 2014, 591-609.

Bud, Alexander. "The End of Nollywood's Guilded Age? Marketers, the State and the Struggle for Distribution." Critical African Studies, vol. 6, no. 1, 2014, pp. 91-121.

Burri, Mira. "Cultural Protectionism 2.o: Updating Cultural Policy Tools for the Digital Age." Transnational Culture in a Digital Age, edited by Sean A. Pager and Adam Candeub, Edward Elgar Publishing, 2012, pp. 182-202.

Ch'oe, Pyŏng-il. Culture and Trade in the APEC: Case of Film Industry in Canada, Mexico and Korea. Korea Institute for International Economic Policy, 2002.

Chon, Margaret. "The Romantic (Collective) Author." Vanderbilt Journal of Entertainment and Technology Law, vol. 14, 2012, pp. 829-849.

Cowen, Tyler. Creative Destruction: How Globalization Is Changing the World's Cultures. Princeton UP, 2002.

Craig, Carys J. "Reconstructing the Author-Self: Some Feminist Lessons for Copyright Law." American University Journal of Gender, Social Policy \& Law, vol. 15, no. 2, 2007, pp. 207-268.

Curtis, Johnlee Scelba. "Culture and the Digital Copyright Chimera: Assessing the International Regulatory System of the Music Industry in Relation to Cultural Diversity." International Journal of Cultural Property, vol. 13, 2006, pp. 59-97.

Danaher, Brett, et. al. "Copyright Enforcement in the Digital Age: Empirical Evidence and Policy Implications." Communications of the ACM, vol. 6o, no. 2, 2017, pp. 68-75.

Desai, Rachana. "Copyright Infringement in the Indian Film Industry." Vanderbilt Journal of Entertainment \& Technology Law, vol. 7, no. 2, 2005, pp. 259-78. 
Elberse, Anita. Blockbuster: Hit-Making, Risk-Taking, and the Big Business of Entertainment. Henry Holt, 2013.

Elkin-Koren, Niva. "The Changing Nature of Books and the Uneasy Case for Copyright." George Washington Law Review, vol. 79, 2011, pp. 101-133.

Ewa Fabian, "Blockchain, Digital Music and Lex Mercatoria." U.S.-China Law Review, vol. 14. 2017, pp. 852-63.

Fishman, Joseph P. “Creating Around Copyright." Harvard Law Review, vol. 128, 2015, pp. 1333-1404.

Gautam, S Zubin. "The Murky Waters of First Sale: Price Discrimination and Downstream Control in the Wake of Kirtsaeng v. John Wiley \& Sons, Inc." Berkeley Technology Law Journal, vol. 29, 2014, pp. 717-58.

Gervais, Daniel, and Dashiell Renaud. "The Future of United States Copyright Formalities: Why We Should Prioritize Recordation, and How to Do It," Berkeley Technology Law Journal, vol. 28, no. 3, 2013, pp. 1459-1496.

Giorcelli, Michela, and Petra Moser. "Copyrights and Creativity: Evidence from Italian Operas." Working paper, revised 3 Aug. 2017, https://papers.ssrn.com/sol3/papers. cfm?abstract_id=2505776. Accessed 20 Nov. 2018.

Goldstein, Paul. Copyright's Highway: From Gutenberg to the Celestial Jukebox. Revised edition, Stanford Law \& Politics, 2003.

Greene, K.J. "Intellectual Property at the Intersection of Race and Gender: Lady Sings the Blues." American University Journal of Gender, Social Policy \& Law, vol. 16, 2008, pp. 365-385.

Hazucha, Branislav. "Cultural Diversity and Intellectual Property Rights: Friends or Foes?" Cultural Diversity in International Law: The Effectiveness of the UNESCO Convention on the Protection and Promotion of the Diversity of Cultural Expressions, edited by Hanania, Lilian Richieri, Routledge, 2014, pp. 107-120.

He, Guangyue. "Copyright Licensing and the Translation of Scholarly Texts: The Impact of Creative Commons Licensing on English-Chinese Translations." Thesis. The University of Oxford, August 2010.

Heald, Paul J. "How Copyright Keeps Works Disappeared." Journal of Empirical Legal Studies, vol. 11, no. 4, 2014, pp. 829-866.

Hughes, Justin. "Motion Pictures, Markets, and Copylocks." George Mason Law Review, vol. 23, 2016, pp. 941-966.

--. " 'Recoding' Intellectual Property and Overlooked Audience Interests." Texas Law Review, vol. 77, 1999, pp. 923-1010.

Internet Policy Task Force. "Copyright Policy, Creativity, and Innovation in the Digital Economy," U.S. Department of Commerce, July 2013.

Jacques, Sabine, Krzysztof Garstka, and John Street. The Impact on Cultural Diversity of Automated Anti-Piracy Systems as Copyright Enforcement Mechanisms: An Empirical Study of Youtube's Content ID Digital Fingerprinting Technology. Non-CCP Working Paper. University of East Anglia, Centre for Competition Policy, January 2017.

Joo, Thomas W. "Remix Without Romance." Connecticut Law Review, vol. 44, 2011, pp. 415-79. 
Kapczynski, Amy. "The Cost of Price: Why and How to Get Beyond Intellectual Property Internalism." UCLA Law Review, vol. 59, 2012, pp. 970-1026.

Keen, Andrew. Cult of Amateur: How Today's Internet Is Killing Our Culture. Doubleday, 2007.

$\mathrm{Ku}$, Raymond S.K., Jiayang Sun, and Yiying Fan. "Does Copyright Law Promote Creativity? An Empirical Analysis of Copyright's Bounty." Vanderbilt Law Review, vol. 62, no. 6, 2009, pp. 1669-1746.

Kulwin, Noah. "The Internet Apologizes ...." New York Magazine, 16 Apr. 2018, nymag. $\mathrm{com} / \mathrm{selectall} / 2018 / 04 /$ an-apology-for-the-internet-from-the-people-who-built-it.html. Accessed Nov. 21, 2018.

Landes, William M., and Richard A. Posner. The Economic Structure of Intellectual Property Law. Harvard UP, 2003.

Lee, Edward. "Warming Up to User-Generated Content." University of Illinois Law Review, vol. 2008, 2008, pp. 1459-1548.

Lemley, Mark. "IP in a World without Scarcity." NYU Law Review, vol. 90, 2015, pp. 460-515.

Lessig, Lawrence. Remix: Making Art and Commerce Thrive in the Hybrid Economy. Penguin, 2008.

Liang, Lawrence. "Piracy, Creativity and Infrastructure: Rethinking Access to Culture." Alternative Law Forum, 2009, https://papers.ssrn.com/sol3/papers.cfm?abstract_ id=1436229. Accessed Nov. 21, 2018.

Liang, Lawrence, and Ravi Sundaram. "Chapter 8: India." Media Piracy in Emerging Economies, edited by Joe Karaganis, Social Science Research Council, 2011.

Liebowitz, Stan. "Generational Cohort Explanation for Findings on Music Quality." Received by Sean Pager, 18 Sept. 2016.

Liu, Jiarui. "Copyright for Blockheads: An Empirical Study of Market Incentive and Intrinsic Motivation." Columbia Journal of Law \& Arts, vol. 38, 2015, pp. 467-548.

--. "The Tough Reality of Copyright Piracy: A Case Study of the Music Industry in China." Cardozo Arts \& Entertainment Law Journal, vol. 27, 2010, pp. 621-61.

Lobato, Ramon. Shadow Economies of Cinema: Mapping Informal Film Distribution. British Film Institute, 2012.

Lunney, Glynn. Copyright's Excess: Money and Music in the US Recording Industry. Cambridge UP, 2018.

Macmillan, Fiona. "Cultural Diversity, Copyright, and International Trade." Handbook of the Economics of Art and Culture, edited by V.A. Ginsburgh and David Throsby, Elsevier, 2014, pp. 411-438.

Manjoo, Farhad. "How the Internet Is Saving Culture, Not Killing It." The New York Times, 15 Mar.2017, www.nytimes.com/2017/03/15/technology/how-the-internet-is-savingculture-not-killing-it.html. Accessed 21 Nov. 2018.

Manuel, Peter. Cassette Culture: Popular Music and Technology in North India. U of Chicago P, 1993.

Merges, Robert P. "The Concept of Property in the Digital Age." Houston Law Review, vol. 45, 2008, pp. 1239-75. 
Miller, Jade L. Nollywood Central. BFI Palgrave, 2016.

Moglen, Eben. "Anarchism Triumphant." First Monday, 2 Aug. 1999, http://firstmonday. org/htbin/cgiwrap/bin/ojs/index.php/fm/article/view/684/594. Accessed Nov. 21, 2018.

Montgomery, Lucy, and Eric Priest. "Copyright and China's Digital Cultural Industries." Handbook of Cultural and Creative Industries in China, edited by Michael Keane, Edward Elgar Publishing, 2016, pp. 339-359.

Nadel, Mark S. "How Current Copyright Law Discourages Creative Output: The Overlooked Impact of Marketing." Berkeley Technology Law Journal, vol. 19, no. 2, 2004, pp. $785-856$.

Napoli, Philip M. "Diminished, Enduring, and Emergent Diversity Policy concerns in an Evolving Media Environment." Transnational Culture in a Digital Age, edited by Sean A. Pager and Adam Candeub, Edward Elgar Publishing, 2012, pp. 165-181.

Netanel, Neil Weinstock. "Copyright and a Democratic Civil Society." Yale Law Journal, vol. 106, 1996, pp. 283-387.

-.. "Market Hierarchy and Copyright in Our System of Free Expression." Vanderbilt Law Review, vol. 53, no. 6, 2000, pp. 1897-1932.

Ouellette, Lisa Larrimore. "Patent Experimentalism." Virginia Law Review, vol. 101, 2015, pp. 65-128.

Pager, Sean. "Accentuating the Positive: Building Capacity for Creative Industries into the Development Agenda for Global Intellectual Property Law." American University International Law Review, vol. 28, 2012, pp. 223-94.

--. "Beyond Culture vs. Commerce: Decentralizing Cultural Protection to Promote Diversity through Trade." Northwestern Journal of International Law and Business, vol. 31, 2011, pp. 63-135.

--. "Folklore 2.o: Preservation through Innovation." Utah Law Review, vol. 2012, 2012, pp. 1835-95.

--. "Making Copyright Work for Creative Upstarts." George Mason Law Review, vol. 22, 2015, pp. 1021-55.

--. "The Role of Copyright in Creative Industry Development." Law E Development Review, vol. 10, 2017, pp. 521-576.

Parc, Jimmyn, and Patrick Messerlin. "The True Impact of Shorter and Longer Copyright Durations: From Authors' Earnings to Cultural Creativity and Diversity." European Centre for International Political Economy, December 2017.

Parc, Jimmyn, Patrick Messerlin, and Hwy-Chy Moon. "The Secret to the Success of K-pop: The Benefits of Well-Balanced Copyrights." European Centre for International Political Economy, April 2016.

Patry, William. "The Failure of the American Copyright System: Protecting the Idle Rich." Notre Dame Law Review, vol. 72, 1997, pp. 907-933.

Pessach, Guy. "Beyond IP-The Cost of Free: Informational Capitalism in a Post IP Era." Osgoode Hall Law Journal, vol. 54, no. 1, 2016, pp. 225-251.

-.. "Copyright Law as a Silencing Restriction on Noninfringing Materials: Unveiling the Scope of Copyright's Diversity Externalities." Southern California Law Review, vol. 76, 2003, pp. 1067-1104. 
Priest, Eric. "Copyright Extremophiles: Do Creative Industries Thrive or Just Survive in China's High-Piracy Environment?” Harvard Journal of Law E Technology, vol. 27, no. 2, 2014, pp. 467-541.

Ranaivoson, Heritiana. Measuring Cultural Diversity: A Review of Existing Definitions. Research Paper. UNESCO, 2007.

Ranaivoson, Heritiana, Maria Iglesias, and Anna Vondracek. "The Costs of Licensing for Online Music Services: An Exploratory Analysis for European Services." Michigan State University International Law Review, vol. 21, no. 3, 2013, pp. 665-686.

Reidel, Ivan. "The Taylor Swift Paradox: Superstardom, Excessive Advertising and Blanket Licenses." NYU Journal of Law \& Business, vol. 7, 2011, pp. 731-809.

Rizk, Nagla. "From De Facto Commons to Digital Commons? The Case of Egypt's Independent Music Industry." Innovation \& Intellectual Property: Collaborative Dynamics in Africa, edited by Jeremy de Beer, Chris Armstrong, Chidi Oguamanam, and Tobias Schonwetter, UCT Press, 2014.

Samuelson, Pamela. "The Copyright Principles Project: Directions for Reform." Berkeley Technology Law Journal, vol. 25, 2010, pp. 1175-1246.

Santos, Ana. "Nurturing Creative Industries in the Developing World: The Case of the Alternative Systems of Music Productions and Distribution." Michigan State International Law Review, vol. 21, 2013, pp. 601-645.

Seabrook, John. "Factory Girls: Cultural Technology and the Making of K-pop." The New Yorker, 8 Oct. 2012, https://www.newyorker.com/magazine/2012/10/o8/factory-girls-2. Accessed 21 Nov. 2018.

Shaver, Lea. "Copyright and Inequality." Washington University Law Review, vol. 92, no. 1, 2014, pp. 117-168.

Sherman, Cary. "What Wikipedia Won't Tell You." The New York Times, 7 Feb. 2012, https://www.nytimes.com/2012/o2/o8/opinion/what-wikipedia-wont-tell-you.html. Accessed 21 Nov. 2018.

Shim, Doobo. "Hybridity, and the Rise of Korean Popular Culture in Asia." Media, Culture, and Society, vol. 28, 2006, pp. 25-44.

Shur-Ofry, Michal. "Copyright, Complexity and Cultural Diversity - A Skeptic's View." Transnational Culture in a Digital Age, edited by Sean A. Pager and Adam Candeub, Edward Elgar Publishing, 2012.

--. "IP and the Lens of Complexity." IDEA: The Intellectual Property Law Review, vol. 54, 2014, pp. 55-102.

Sprigman, Christoper, and Kal Raustiala. The Knockoff Economy: How Imitation Sparks Innovation. Oxford UP, 2012.

Strandburg, Katherine J. "Free Fall: The Online Market's Consumer Preference Disconnect." University of Chicago Legal Forum, vol. 2013, pp. 95-172.

Street, John. "The Popular, the Diverse and the Excellent: Political Values and UK Cultural Policy." International Journal of Cultural Policy, vol. 17, no. 4, 2011, pp. 380-393.

Sunder, Madhavi, "IP3." Stanford Law Review, vol. 59, 2006, pp. 257-332. 
Telang, Rahul, and Joel Waldfogel. Piracy and New Product Creation: A Bollywood Story. Working Paper, Carnegie Mellon University, 6 Aug. 2014, https://papers.ssrn.com/sol3/ papers.cfm?abstract_id $=2478755$. 2014. Accessed 21 Nov. 2018.

Towse, Ruth. "What We Know, What We Don't Know, and What Policy-Makers Would Like Us to Know About the Economics of Copyright." Review of Economic Research on Copyright Issues, vol. 8, no. 2, 2011, pp. 101-120.

Turow, Scott. "The Slow Death of the American Author." New York Times, 7 April 2013.

Tushnet, Rebecca. "Free to Be You and Me? Copyright and Constraint." Harvard Law Review Forum, vol. 128, 2015, pp. 125-136.

Voon, Tania. Cultural Products and the World Trade Organization (Cambridge Studies in International and Comparative Law Series). Cambridge UP, 2007.

Waldfogel, Joel. "Cinematic Explosion: New Products, Unpredictability, and Realized Quality in the Digital Era." Journal of Industrial Economics, vol. 64, no. 4, 2016, pp. 755-772.

--. "How Digitization Has Created a Golden Age of Music, Movies, Books, and Television." Journal of Economic Perspectives, vol. 31, no.3, 2017, pp. 195-214.

Walker, Robert Kirk, and Ben Depoorter. "Unavoidable Aesthetic Judgments in Copyright Law: A Community of Practice Standard." Northwestern University Law Review, vol. 109, 2015, pp. 343-81.

Whaley, Floyd. "New Ambitions in Philippine Film Business." The New York Times, 7 May 2012, http://www.nytimes.com/2012/05/o8/business/global/new-ambitions-inphilippine-film-business.html?_r=o. Accessed 21 Nov. 2018.

Willms, Jessie. "Is Blockchain-Powered Copyright Protection Possible?" Bitcoin Magazine, 16 May 2018, https://bitcoinmagazine.com/articles/is-blockchain-powered-copyrightprotection-possible-1470758430/. Accessed 21 Nov. 2018.

Yoo, Christopher S. "Copyright and Product Differentiation." New York University Law Review, vol. 79, 2004, pp. 212-80. 